\title{
ARTICLES
}

\section{Long-Chain Fatty Acid Oxidation during Early Human Development}

\author{
NADIA A. OEY, MARGARETHE E.J. DEN BOER, FRITS A. WIJBURG, MICHEL VEKEMANS, \\ JOËLLE AUGÉ, CÉLINE STEINER, RONALD J.A. WANDERS, HANS R. WATERHAM, \\ JOS P.N. RUITER, AND TANIA ATTIÉ-BITACH
}

Departments of Pediatrics and Clinical Chemistry [N.A.O., M.E.J.d.B., F.A.W., R.J.A.W., H.R.W, J.P.N.R], Academic Medical Centre, University of Amsterdam, 1105 AZ, Amsterdam, The Netherlands, Département de Génetique et Unité [M.V., J.A., C.S., T.A-B.], INSERM U-393, Hôpital Necker-Enfants Malades, 75743 Paris Cedex 15, France

\section{ABSTRACT}

Patients with very long-chain acyl-CoA dehydrogenase (VLCAD) and long-chain 3-hydroxyacyl-CoA dehydrogenase (LCHAD)/mitochondrial trifunctional protein (MTP) deficiency, disorders of the mitochondrial long-chain fatty acid oxidation, can present with hypoketotic hypoglycemia, rhabdomyolysis, and cardiomyopathy. In addition, patients with LCHAD/MTP deficiency may suffer from retinopathy and peripheral neuropathy. Until recently, there was no indication of intrauterine morbidity in these disorders. This observation was in line with the widely accepted view that fatty acid oxidation (FAO) does not play a significant role during fetal life. However, the high incidence of the gestational complications acute fatty liver of pregnancy and hemolysis, elevated liver enzymes, and low platelets syndrome observed in mothers carrying a LCHAD/MTP-deficient child and the recent reports of fetal hydrops due to cardiomyopathy in MTP deficiency, as well as the high incidence of intrauterine growth retardation in children with LCHAD/MTP deficiency, suggest that FAO may play an important role during fetal development. In this study, using in situ hybridization of the VLCAD and the LCHAD mRNA, we report on the expression of genes involved in the mitochondrial oxidation of long-chain fatty acids during early human development. Furthermore, we measured the enzymatic activity of the VLCAD, LCHAD, and carnitine palmitoyl-CoA transferase 2 (CPT2) enzymes in different human fetal tissues. Human embryos (at d 35 and 49 of development) and separate tissues (5-20 wk of development) were used. The results show a strong expression of VLCAD and LCHAD mRNA and a high enzymatic activity of VLCAD, LCHAD, and CPT2 in a number of tissues, such as liver and heart. In addition, high expression of LCHAD mRNA was observed in the neural retina and CNS. The observed pattern of expression during early human development is well in line with the spectrum of clinical signs and symptoms reported in patients with VLCAD or LCHAD/ MTP deficiency. (Pediatr Res 57: 755-759, 2005)

Abbreviations
ACAD, acyl-CoA dehydrogenase (EC 1.3.99)
AFLP, acute fatty liver of pregnancy
CPT1, carnitine palmitoyl-CoA transferase 1 (EC 2.3.1.21)
CPT2, carnitine palmitoyl-CoA transferase 2 (EC 2.3.1.21)
FAO, fatty acid oxidation

HELLP, hemolysis, elevated liver enzymes, and low platelets

IUGR, intrauterine growth retardation

LCHAD, long-chain 3-hydroxyacyl-CoA dehydrogenase (EC 1.1.1.35)

MTP, mitochondrial trifunctional protein (EC 4.2.1.17, EC

1.1.1.35, EC 2.3.1.16)

VLCAD, very long-chain acyl-CoA dehydrogenase (EC 1.3.99.13)
Mitochondrial oxidation of fatty acids plays a critical role in energy metabolism after birth. The heart preferentially uses fatty acids as a substrate for energy production. In addition, during moderately severe exercise, skeletal muscle predomi-

Received June 30, 2004; accepted November 2, 2004.

Correspondence: Frits A. Wijburg, M.D., Ph.D., Department of Pediatrics (G8-205), Emma Children's Hospital AMC, Academic Medical Centre, PO Box 22660, NL-1100 DD Amsterdam, The Netherlands; e-mail: F.A.Wijburg@amc.uva.nl

EURExpress and HMR (Hoechst-Marion-Roussel) are acknowledged for financial support.

DOI: 10.1203/01.PDR.0000161413.42874.74 nantly utilizes fatty acids as an energy source. In the liver, FAO is used during fasting to produce ketone bodies that are exported from the liver and can be used for energy production by peripheral tissues such as the brain. Mitochondrial FAO of long-chain fatty acids involves the concerted action of a multitude of enzymes. This process starts with the carnitinemediated transfer of the long-chain fatty acids, activated to their CoA esters, over the mitochondrial inner-membrane. This involves the activity of three enzymes: CPT1, carnitine acylcarnitine translocase (CACT), and CPT2. Once inside the 
mitochondria, the fatty acyl-CoA esters undergo $\beta$-oxidation via a four-step mechanism, involving dehydrogenation, hydration, another dehydrogenation, and thiolytic cleavage. Oxidation of long-chain fatty acids starts with the first dehydrogenation catalyzed by the VLCAD enzyme. The next three steps are catalyzed by the MTP. MTP is a heterooctamer of four $\alpha$ and four $\beta$-subunits. It harbors the activity of three out of the four enzymes required for the oxidation of long-chain fatty acids: the long-chain enoyl-CoA hydratase, LCHAD, and the long-chain 3-keto-acyl-CoA thiolase. The $\alpha$-subunit carries the long-chain enoyl-CoA hydratase and the LCHAD activities, whereas the $\beta$-subunit harbors the long-chain 3-ketoacyl-CoA thiolase activity. The importance of the mitochondrial FAO is stressed by the existence of a variety of different genetic disorders in which mitochondrial FAO is impaired (1). In general, clinical signs and symptoms of FAO disorders are related to the lack of energy for metabolic functions, resulting in hypoketotic hypoglycemia and multiple organ failure. In addition, patients with inborn errors of long-chain FAO, such as VLCAD deficiency (2,3), isolated LCHAD deficiency (4), and complete MTP deficiency (5), present with a variety of severe clinical problems, such as cardiomyopathy, retinopathy, and peripheral neuropathy, presumably due to the accumulation of toxic long-chain acyl-CoA esters.

In contrast, before birth, the fetus is considered to be primarily dependent on glucose oxidation for energy production (6). There are four reasons for this. Firstly, glucose is abundantly supplied by the mother and rapidly crosses the placenta. Secondly, in animal studies (e.g. in rat, rabbit and lamb) a low mRNA expression and a low activity of FAO enzymes is detected in fetal heart and liver, with a rapid rise of mRNA levels and subsequent increase in enzymatic activity directly after birth (7-9). Thirdly, the abundance of glucose as a substrate for the fetus results in high concentrations of malonyl-CoA, which inhibits CPT1. This prevents the entry of long-chain fatty acids via the carnitine-mediated transfer CPT1-CACT-CPT2 system into the mitochondria and thus results in a low activity of long-chain FAO. In addition, fetal CPT1 levels are low and highly sensitive to malonyl-CoA (8). Fourthly, although inborn errors of mitochondrial FAO can present with clinical signs and symptoms immediately after birth, fetal disease has, until recently, not been reported in this group of disorders (1).

In the last decade, however, several reports have linked the presence of two defects in the mitochondrial long-chain FAO in the fetus, namely isolated LCHAD deficiency and MTP deficiency, to the severe pregnancy complications AFLP and the HELLP syndrome (4,10-13). In addition, recent studies have noticed a higher frequency of prematurity, IUGR, and intrauterine death in association with isolated LCHAD deficiency and MTP deficiency $(4,11,14)$. These findings suggest that FAO plays an important role in the human fetal-placental unit, which would be in contrast to the results obtained in animal studies.

To our knowledge, the role of mitochondrial long-chain FAO has not been investigated during early human development. We investigated the expression of two genes involved in long-chain FAO, VLCAD and LCHAD, in the human embryo during development, using in situ hybridization as well as enzymatic studies.

\section{MATERIALS AND METHODS}

Sections. Human embryos and fetal tissues were collected from legally terminated pregnancies in agreement with French law as well as the recommendations of the local ethics committee. Written informed maternal consent was obtained after termination of pregnancy. Tissues were prepared as described previously (15). For the in situ hybridization studies in sections of intact embryos, two embryos, at Carnegie stage 14 (d 35 of development) and stage 18 (d 49 of development), were used. For later hybridization studies, heart, lung, and eye from three fetuses $(8,9$, and $20 \mathrm{wk}$ of development) were used. Also, separate frozen organs from five different fetuses $(5,6,7.5,8$, and 8.5 wk of development) were used for enzymatic studies.

Hybridization probes. Templates used for the generation of hybridization probes for VLCAD and LCHAD were amplified by PCR from human genomic DNA using the following oligonucleotide primers: VLCAD-forward 5'-AAT TGT GGT GGA GAG GGG C-3'; VLCAD-reverse 5'-AAA CTG GGT ACG ATT AGT GGC-3'; LCHAD-forward 5'-AAT TCT TCC TGT ACG ATT GGG G-3'; LCHAD-reverse 5'-AAT CTA ATG GTC TTA ATT CAG GC-3'. After amplification, the PCR fragments were purified and subcloned into the pGEM-T vector (Invitrogen, Carlsbad, CA), which contains both a T7 and a Sp6 promoter. The inserts were verified by sequencing to exclude PCRintroduced errors. To generate a sense or an antisense RNA probe, the pGEM-T vector containing VLCAD and LCHAD was digested with $S a L I$ for the T7 promoter or SphI for the Sp6 promoter, respectively. The linearized plasmids were purified with phenol/chloroform extraction and dissolved in TE at $200 \mathrm{ng} / \mathrm{mL}$. $\alpha\left[{ }^{35} \mathrm{~S}\right] \mathrm{UTP}-$ labeled probes were generated from these templates as described previously (15).

Hybridization. Hybridization and posthybridization washes were carried out according to standard protocols (16). Slides were dehydrated, exposed to Biomax MR x-ray films (Amersham Pharmacia Biotech UK Ltd., Little Chalfont, Buckinghamshire, UK) for $3 \mathrm{~d}$, dipped in Kodak NTB2 emulsion (Eastman Kodak, Rochester, NY) for 3 wk at $+4^{\circ} \mathrm{C}$. Developed and toluidine blue counterstained slides were analyzed with dark- and bright-field illumination. Adjacent slides were hematoxylin/eosin/saffron stained for histologic studies.

No hybridization signal was detected with the $\alpha\left[{ }^{35} \mathrm{~S}\right]$-labeled sense probes.

Enzymatic studies. Tissue samples, stored at $-70^{\circ} \mathrm{C}$, were thawed. The activity of VLCAD was measured as described elsewhere (17), using palmitoyl-CoA as substrates. The activity of LCHAD was determined as previously described (18). The activity of CPT2 was measured radiochemically, essentially as described by Slama et al. (19). Control values for enzymatic activity in human liver were measured in our laboratory, using the same techniques as used for embryonic studies.

\section{RESULTS}

We studied the expression of the genes encoding the longchain FAO enzymes VLCAD and LCHAD, using in situ hybridization of human embryos at 35 and $49 \mathrm{~d}$ of development [Carnegie stages (CS) 14 and 18] and of tissue sections of fetuses at 8, 9, and 20 wk of development. In addition, VLCAD and LCHAD activities were measured enzymatically in fetal heart, liver, and brain, between 5 and 8.5 wk of development. The expression pattern of VLCAD and LCHAD genes during human development is presented in Figures 1 and 2.

VLCAD. At CS14, $35 \mathrm{~d}$ of development, the VLCAD gene was ubiquitously expressed with a strong expression in liver (Fig. $1 B$ and $E$ ). At CS18, $49 \mathrm{~d}$ of development, its strong liver expression was still conserved (Fig. $1, H$ and $K$ ). A weak expression was also observed in the developing kidney (Fig. $1 K$ ), heart (not shown), and digestive tract epithelium (Fig. $1 K$ ). At early fetal stages (Fig. 2), VLCAD was ubiquitously expressed in all tissues examined. The expression was particularly high in the heart and great vessels (Fig. 2B), the lung (Fig. $2 F$ ), and the neural retina (Fig. $2 J$ ) when compared with the control sense probes (Fig. $2 D, H$, and $L$ ).

$\boldsymbol{L C H A D}$. Interestingly, the LCHAD gene expression was different from the VLCAD gene expression. At $35 \mathrm{~d}$ of development, a weak LCHAD gene expression was found in both 


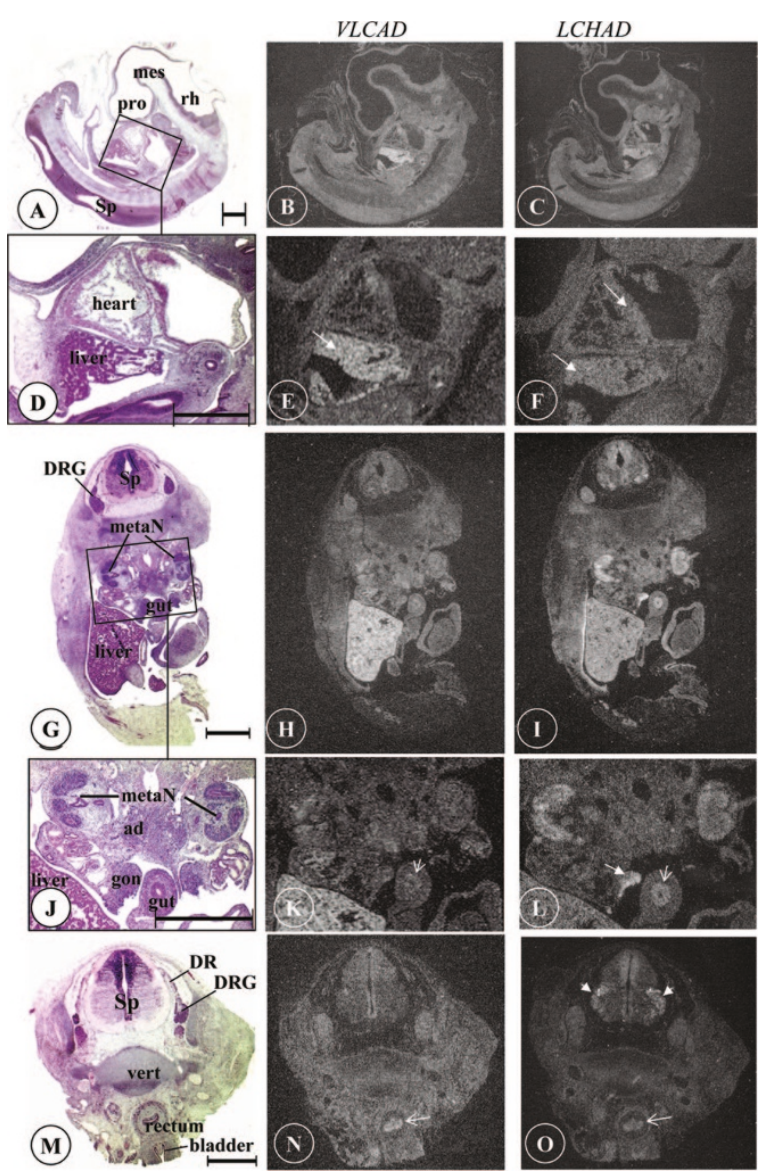

Figure 1. VLCAD and LCHAD gene expression in human embryos. $A, D, G$, $J, M$ are hematoxylin-eosin $(H E)$-stained sections, adjacent to the slides hybridized with the $\operatorname{VLCAD}(B, E, H, K, N)$ and $\operatorname{LCHAD}(C, F, I, L, O)$ genes, respectively. $A-F$ : sagittal sections of a CS14 (35 d) human embryo. $D-F$ are enlarged views of $A-C$, showing the ubiquitous VLCAD gene expression, with a strong signal in liver $(E$, arrow) and a weak but specific LCHAD expression in heart and liver $(F$, arrows). $G-O$ : Transverse sections through a CS18 (49 d) human embryo at the abdominal $(G-L)$ and caudal region level $(M-O) . J-L$ are enlarged views of $G-I$. The VLCAD gene is still ubiquitously expressed with a strong signal in liver $(H, K) . I-O$ : LCHAD gene expression is observed in the metanephros (metaN), gonads (gon, arrow in $L$ ), gut epithelium (I, $O$, open arrows), liver, dorsal root ganglia $(D R G)$, and anterior part of the spinal cord $(S p)$ as shown by arrowheads in $O$. Ad, adrenal glands; $D R$, dorsal root; mes, mesencephalon; pro, prosencephalon; rh, rhombencephalon; vert, vertebrae. Scale bar (HE-stained sections) $=1 \mathrm{~mm}$.

heart and liver (Fig. $1 C$ and $F$ ). At CS18, in addition to the liver (Fig. $1 I$ ) and heart (not shown), LCHAD was specifically and strongly expressed in the metanephros, gonads (Fig. $1 L$ ), and the developing gut epithelium (Fig. $1 L$ and $O$ ). In the nervous system, LCHAD was expressed in developing brain and neural retina (data not shown), as well as in a subpopulation of cells of the anterior horn of the spinal cord, and in dorsal root ganglia, (Fig. 1I and $O$ ). This pattern of $L C H A D$ gene expression was again observed during fetal stages (Fig. 2). In the heart, $L C H A D$ was strongly expressed in the myocardial tissue, but no signal was detected in the great vessels (Fig. 2C). In the lung, $L C H A D$ expression was restricted to epithelial cells (Fig. $2 G$ ). In the CNS, a strong expression of the $L C H A D$ gene was observed in the neural retina (Fig. $2 K$ ) and the motor neurons of the anterior horn of the spinal cord (Fig. $2 \mathrm{~N}$ ) when compared with controls (Fig. 2O).

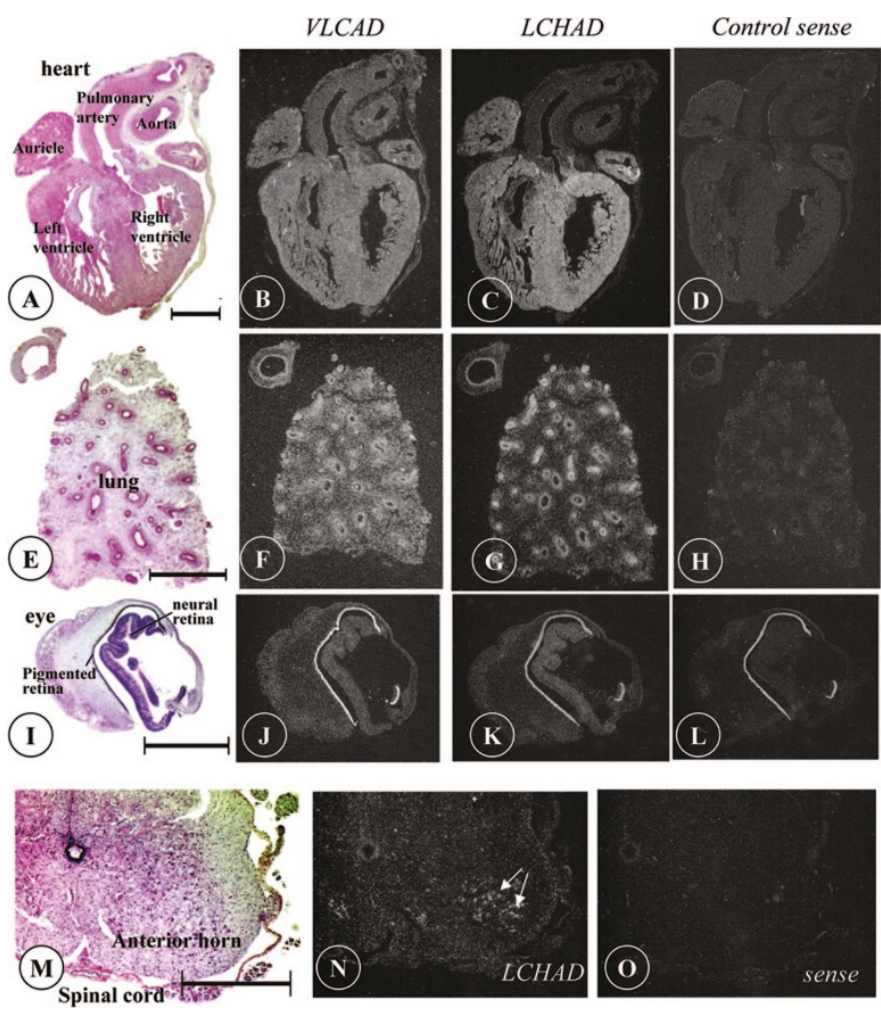

Figure 2. VLCAD and LCHAD gene expression in fetal tissues. A, E, I, $M$ are hematoxylin-eosin $(H E)$-stained sections, adjacent to the slides hybridized respectively with the $\operatorname{VLCAD}(B, F, J), \operatorname{LCHAD}(C, G, K, N)$ antisense and sense $(D, H, L, O)$ probes. Transverse sections of a 9-wk fetal heart $(A-D)$ and lung $(E-H)$. VLCAD is ubiquitously expressed throughout the heart and great vessels $(B)$, the lung $(F)$. In contrast, no expression is detected in the great vessels $(B)$. In the lung, LCHAD expression is restricted to the epithelium. $I-J$ : Parasagittal section through an 8-wk eye. In the neural retina, LCHAD gene expression is slightly higher than the VLCAD gene expression. Note the false-positive signal given by the pigmented retina also observed with the sense probe. $M-O$ : Transverse section through the spinal cord of a 20 -wk fetus, showing strong expression of the LCHAD gene in motor neurons of the anterior horn (arrows), compared with the sense probe $(O)$. Scale bars (HEstained sections) $=1 \mathrm{~mm}$.

Enzymatic studies. The enzymatic activity of VLCAD and LCHAD could be clearly detected in heart, liver, and brain tissue of human embryos (Table 1). CPT2 activity was high in

Table 1. Activities of FAO enzymes during early human development and in control human liver

\begin{tabular}{lcc}
\hline $\begin{array}{c}\text { Tissue, developmental } \\
\text { week }\end{array}$ & VLCAD & LCHAD \\
\hline Heart, 5 wk & 2.53 & 121 \\
Heart, 6 wk & 3.27 & 129 \\
Heart, 7.5 wk & 3.18 & 151 \\
Heart, 8 wk & 4.02 & 142 \\
Liver, 5 wk & 3.37 & 169 \\
Liver, 6 wk & 7.60 & 207 \\
Liver, 8.5 wk & 4.18 & 126 \\
Brain, 6 wk & 1.12 & 95 \\
Brain, 7.5 wk & 0.54 & 47 \\
Control adult liver & 7.20 & 313 \\
Control skeletal muscle & 5.5 & 46 \\
\hline
\end{tabular}

Activities are expressed as $\mathrm{nmol} / \mathrm{min} / \mathrm{mg}$ protein. Control human liver: $n=$ 3 for VLCAD and $n=10$ for LCHAD. Control human skeletal muscle: $n=$ 3 for VLCAD and $n=4$ for LCHAD. 
heart, liver, and brain of the 6-wk-old embryo: 49.6, 65.5, and $30.1 \mathrm{nmol} / \mathrm{min} / \mathrm{mg}$ protein, respectively (control adult liver, 57 $\mathrm{nmol} / \mathrm{min} / \mathrm{mg}$ protein; $n=3$ ). Although enzyme activity was generally higher in adult human liver, which has a high FAO capacity, the difference was only small.

\section{DISCUSSION}

In contrast to the widely accepted view, the present study indicates that FAO may play an important role during early human development. Recent studies in human placenta already demonstrated a remarkable high activity of FAO enzymes $(20-22)$. In placenta, the activity of the enzymes LCHAD and short-chain 3-hydroxyacyl-CoA dehydrogenase (SCHAD) were inversely correlated with gestational age (20). Furthermore, the activity of CPT2 and of VLCAD was higher in term human placenta than in adult human liver (21). As the human placenta is of embryonic origin, these results indicate that FAO takes place in fetal tissue, suggesting a possible role for a disturbed placental FAO in the pathogenesis of the pregnancy complications AFLP and HELLP syndrome. The results of our study demonstrate mRNA expression of the long-chain FAO enzymes VLCAD and LCHAD as well as enzymatic activity of VLCAD, LCHAD, and CPT2 during early human development. These observations are well in line with the high activity of FAO in human placenta and strongly suggest that not only the placenta, but also the human embryo utilizes fatty acids as a substrate for energy production.

Studies by Ibdah and co-workers (23) revealed that MTPdeficient knockout mice suffer from IUGR. IUGR has also been reported in humans as a consequence of fetal MTP deficiency $(5,11,14)$. Although in humans the high incidence of IUGR may be associated with the maternal complications HELLP syndrome and AFLP, IUGR in MTP-deficient mice could not be attributed to placental nor to maternal disease (23). Our study revealed significant mRNA expression and high enzymatic activity of LCHAD and VLCAD in numerous tissues during early human development. Therefore, it is not surprising that isolated LCHAD deficiency, MTP deficiency, or VLCAD deficiency can result in fetal disease with IUGR as a consequence. In addition, a recent study in long-chain acylCoA dehydrogenase (LCAD) deficient knockout mice revealed disrupted blastocoele formation resulting in a significantly increased rate of early fetal loss (24), underlining the importance of FAO during very early embryonic development. These observations in mice, in combination with the results of our study, suggest that long-chain FAO defects might be associated with very early fetal loss, perceived as decreased fertility, in humans. Although this has, to our knowledge, not been reported, a decreased fertility in mothers who gave birth to children with a long-chain FAO defect might have been easily overlooked, and studies to establish such a relation are necessary.

Cardiomyopathy is a frequent and often fatal complication of long-chain FAO enzyme defects, including VLCAD deficiency, isolated LCHAD deficiency, and complete MTP deficiency. Presumably, it results from the accumulation of arrhythmogenic long-chain acylcarnitines (25). In addition, fetal hydrops due to intrauterine cardiomyopathy was reported recently in a child with MTP deficiency $(5,26)$. Hydrops fetalis due to cardiomyopathy was also reported in relation to carnitine deficiency (27). These observations suggest that longchain FAO is taking place in the myocardium during intrauterine life. Our study, conducted in human embryos, shows a strong expression and high activity of LCHAD and VLCAD in myocardial tissue (Fig. $2 B$ and $C$; Table 1). If the fetal heart uses fatty acids as an important substrate for the production of ATP, it is likely that intrauterine cardiomyopathy can result from a defective long-chain FAO. In that respect, however, it is surprising that fetal hydrops has not been reported more frequently in relation to long-chain FAO deficiency.

The observed expression pattern of LCHAD mRNA in human embryos correlates very well with clinical signs and symptoms observed in patients with isolated LCHAD deficiency and complete MTP deficiency, suggesting that postnatal expression of LCHAD mRNA follows the pattern of prenatal expression during early development. Pigmentary retinopathy is an important feature of LCHAD deficiency, and has not been reported in any other FAO defect. Recently, Tyni and coworkers (28) demonstrated that FAO is taking place in cultured porcine retinal pigment epithelium cells. This suggests that FAO may play an important role in the retina. Although pigmentary retinopathy has not been observed at birth, it has been detected in LCHAD-deficient patients at 4 mo of age (29). The LCHAD mRNA expression we observed in the neural retina (Fig. $2 K$ ) suggests that long-chain FAO plays a role in the developing human retina. Therefore, retinal damage observed in LCHAD- and MTP-deficient patients may already have started in utero.

Another unique feature of LCHAD and MTP deficiency is the presence of a progressive peripheral neuropathy, reported in more than $50 \%$ of MTP deficient patients (4). This symptom is not reported in any other FAO defect. Nerve conduction velocity was determined in a few patients with peripheral neuropathy and showed axonal neuropathy with sensory predominance (30-32). Nerve biopsy was normal in one patient, but revealed demyelinization and axonal neuropathy in two others $(30,32)$. Our human embryo studies showed LCHAD mRNA expression in the developing CNS. In particular, LCHAD mRNA could be detected in the anterior horn of the spinal cord at $49 \mathrm{~d}$ of development. In addition, the LCHAD gene was also clearly expressed in the motor neurons of the anterior horn of the spinal cord at $20 \mathrm{wk}$ of development (Fig. $2 N$ ), whereas VLCAD expression was very weak (data not shown).

Recently, severe lung disease was reported in several patients with LCHAD deficiency, as Lundy and co-workers (33) reported acute respiratory distress syndrome in four unrelated patients with LCHAD deficiency. Lung disease has previously not been associated with FAO disorders. The distinct expression of LCHAD mRNA in epithelial cells of the lung as observed in our study fits remarkably well with this recent finding of acute respiratory distress syndrome complicating LCHAD deficiency.

It is difficult to explain the discrepancy between the LCHAD and VLCAD expression patterns as observed in the CNS of the developing human embryo, as the mitochondrial FAO involves 
the concerted action of all enzymes. An explanation might be that MTP has an additional metabolic role in the developing CNS, including the retina, as already suggested by Tyni et al. (28). However, such an additional role has never been detected at the biochemical level. Another possible explanation could be that there are other enzymes involved, with activities overlapping VLCAD activity. Zhang et al. (34) identified a novel homologue of an acyl-CoA dehydrogenase (ACAD) enzyme, ACAD 9, with activity with palmitoyl-CoA (C16:0), and stearoyl-CoA (C18:0). It shares approximately 65\% similarity with human VLCAD, and ACAD 9 mRNA is ubiquitously expressed in most human tissues, with high level of expression in heart, skeletal muscles, kidney, liver, and, interestingly, brain. Activity of VLCAD overlapping enzymes, such as ACAD 9 or LCAD (35) might take over the activity from VLCAD in those tissues lacking VLCAD expression but expressing LCHAD mRNA, during early development.

Finally, our study also demonstrates that long-chain FAO is present in other tissues during early human development. In particular, a strong expression of LCHAD is observed in gut, gonadal tissue, and metanephros. We are not aware of any involvement of these tissues in patients with long-chain FAO disorders. Nevertheless, we believe that patients with inborn errors of long-chain FAO should also be monitored for gastrointestinal, gonadal, and renal complications during long-term follow-up.

In summary, here we describe a detailed study of the expression of the long-chain FAO VLCAD and LCHAD genes as well as their enzymatic activity during early human development. In contrast to the widely accepted view that embryologic development depends on glucose as the major source of metabolic energy, our results clearly show that long-chain FAO is also taking place in the human embryo. Our observations are well in line with the pattern of clinical signs and symptoms observed in patients with VLCAD and LCHAD/MTP deficiency. Additional studies on the expression of different ACAD enzymes in different tissues may reveal the cause of the observed differences in VLCAD and LCHAD deficiency.

Acknowledgments. The authors thank Féréchté Razavi for helpful discussions.

\section{REFERENCES}

1. Roe CR, Ding J 2001 Mitochondrial fatty acid oxidation disorders. In: Scriver CR, Beaudet AL, Sly WS, Valle D (eds) The Metabolic and Molecular Basis of Inherited Disease. McGraw-Hill, New York, pp 2308-2311

2. Vianey-Saban C, Divry P, Brivet M, Nada M, Zabot MT, Mathieu M, Roe C 1998 Mitochondrial very-long-chain acyl-coenzyme A dehydrogenase deficiency: clinical characteristics and diagnostic considerations in 30 patients. Clin Chim Acta 269:43-62

3. Andresen BS, Olpin S, Poorthuis BJ, Scholte HR, Vianey-Saban C, Wanders R, IJlst L, Morris A, Pourfarzam M, Bartlett K, Baumgartner ER, deKlerk JB, Schroeder LD, Corydon TJ, Lund H, Winter V, Bross P, Bolund L, Gregersen N 1999 Clear correlation of genotype with disease phenotype in very-long-chain acyl-CoA dehydrogenase deficiency. Am J Hum Genet 64:479-494

4. den Boer ME, Wanders RJ, Morris AA, IJlst L, Heymans HS, Wijburg FA 2002 Long-chain 3-hydroxyacyl-CoA dehydrogenase deficiency: clinical presentation and follow-up of 50 patients. Pediatrics 109:99-104

5. den Boer ME, Dionisi-Vici C, Chakrapani A, van Thuijl AO, Wanders RJ, Wijburg FA 2003 Mitochondrial trifunctional protein deficiency: a severe fatty acid oxidation disorder with cardiac and neurological involvement. J Pediatr 142:684-689

6. Jones CT, Rolph TP 1985 Metabolism during fetal life: a functional assessment of metabolic development. Physiol Rev 65:357-430

7. Hainline BE, Kahlenbeck DJ, Grant J, Strauss AW 1993 Tissue specific and developmental expression of rat long- and medium-chain acyl-CoA dehydrogenases. Biochim Biophys Acta 1216:460-468
8. Prip-Buus C, Pegorier JP, Duee PH, Kohl C, Girard J 1990 Evidence that the sensitivity of carnitine palmitoyl transferase I to inhibition by malonyl-CoA is an important site of regulation of hepatic fatty acid oxidation in the fetal and newborn rabbit. Perinatal development and effects of pancreatic hormones in cultured rabbit hepatocytes. Biochem J 269:409-415

9. Bartelds B, Knoester H, Smid GB, Takens J, Visser GH, Penninga L, van der Leij FR, Beaufort-Krol GC, Zijlstra WG, Heymans HS, Kuipers JR 2002 Perinatal changes in myocardial metabolism in lambs. Circulation 102:926-931

10. Wilcken B, Leung KC, Hammond J, Kamath R, Leonard JV 1993 Pregnancy and fetal long-chain 3-hydroxyaxyl coenzyme A dehydrogenase deficiency. Lancet 341:407-408

11. Tyni T, Ekholm E, Pihko H 1998 Pregnancy complications are frequent in long-chain 3-hydroxyacyl-coenzyme A dehydrogenase deficiency. Am J Obstet Gynecol 178:603-608

12. Ibdah JA, Bennett MJ, Rinaldo P, Zhao Y, Gibson B, Sims HF, Strauss AW 1999 A fetal fatty-acid oxidation disorder as a cause of liver disease in pregnant women. N Engl J Med 340:1723-1731

13. Chakrapani A, Olpin S, Cleary M, Walter JH, Wraith JE, Besley GT 2000 Trifunctional protein deficiency: three families with significant maternal hepatic dysfunction in pregnancy not associated with E474Q mutation. J Inherit Metab Dis 23:826-834

14. Yang Z, Zhao Y, Bennett MJ, Strauss AW, Ibdah JA 2002 Fetal genotypes and pregnancy outcomes in 35 families with mitochondrial trifunctional protein mutations. Am J Obstet Gynecol 187:715-720

15. Odent S, Attié-Bitach T, Blayau M, Mathieu M, Aug J, Delezo de AL, Gall JY, Le Marec B, Munnich A, David V, Vekemans M 1999 Expression of the Sonic hedgehog (SHH) gene during early human development and phenotypic expression of new mutations causing holoprosencephaly. Hum Mol Genet 8:1683-1689

16. Wilkinson DG 1992 In situ Hybridization: A Practical Approach. IRL Press, Oxford

17. Wanders RJ, Vreken P, den Boer ME, Wijburg FA, van Gennip AH, IJlst L 1999 Disorders of mitochondrial fatty acyl-CoA $\beta$-oxidation. J Inherit Metab Dis 22:442-487

18. Wanders RJ, IJlst L, Poggi F, Bonnefont JP, Munnich A, Brivet M, Rabier D, Saudubray JM 1992 Human trifunctional protein deficiency: a new disorder of mitochondrial fatty acid beta-oxidation. Biochem Biophys Res Commun 188:11391145

19. Slama A, Brivet M, Boutron A, Legrand A, Saudubray JM, Demaugre F 1996 Complementation analysis of carnitine palmitoyltransferase I and II defects. Pediatr Res 40:542-546

20. Rakheja D, Bennett MJ, Foster BM, Domiati-Saad R, Rogers BB 2002 Evidence for fatty acid oxidation in human placenta, and the relationship of fatty acid oxidation enzyme activities with gestational age. Placenta 23:447-450

21. Oey NA, den Boer ME, Ruiter JP, Wanders RJ, Duran M, Waterham HR, Boer K, van der Post JA, Wijburg FA 2003 High activity of fatty acid oxidation enzymes in human placenta: implications for fetal-maternal disease. J Inherit Metab Dis 26:385-392

22. Shekhawat P, Bennett MJ, Sadovsky Y, Nelson DM, Rakheja D, Strauss AW 2003 Human placenta metabolizes fatty acids: implications for fetal fatty acid oxidation disorders and maternal liver disease. Am J Physiol Endocrinol Metab 284:E1098-E1105

23. Ibdah JA, Paul H, Zhao Y, Binford S, Salleng K, Cline M, Matern D, Benett MJ, Rinaldo P, Strauss AW 2001 Lack of mitochondrial trifunctional protein in mice causes neonatal hypoglycaemia and sudden death. J Clin Invest 107:1403-1409

24. Berger PS, Wood PA 2004 Disrupted blastocoele formation reveals a critical developmental role for long-chain acyl-CoA dehydrogenase. Mol Genet Metab 82:266-272

25. Bonnet D, Martin D, de Lonlay P, Villain E, Jouvet P, Rabier D, Brivet M, Saudubray JM 1999 Arrhythmias and conduction defects as presenting symptoms of fatty acid oxidation disorders in children. Circulation 100:2248-2253

26. Schwab KO, Ensenauer R, Matern D, Uyanik G, Schnieders B, Wanders RA, Lehnert W 2003 Complete deficiency of mitochondrial trifunctional protein due to a novel mutation within the $\beta$-subunit of the mitochondrial trifunctional protein gene leads to failure of long-chain fatty acid $\beta$-oxidation with fetal outcome. Eur J Pediatr 162:90-95

27. Steenhout P, Elmer C, Clercx A, Blum D, Gnat D, van Erum S, Vertongen F, Vamos E 1990 Carnitine deficiency with cardiomyopathy presenting as neonatal hydrops: successful response to carnitine therapy. J Inherit Metab Dis 13:69-75

28. Tyni T, Johnson M, Eaton S, Pourfarzam M, Andrews R, Turnbull DM 2002 Mitochondrial fatty acid $\beta$-oxidation in the retinal pigment epithelium. Pediatr Res 52:595-600

29. Tyni T, Pihko H 1999 Long-chain 3-hydroxyacyl-CoA dehydrogenase deficiency Acta Paediatr 88:237-245

30. Bertini E, Dionisi-Vici C, Garavaglia B, Burlina A, Sabatelli M, Rimoldi M, Bartuli A, Sabetta G, DiDonato S 1992 Peripheral sensory-motor polyneuropathy, pigmentary retinopathy, and fatal cardiomyopathy in long-chain 3-hydroxy-acyl-CoA dehydrogenase deficiency. Eur J Pediatr 151:121-126

31. Vici CD, Burlina AB, Bertini E, Bachmann C, Mazziotta MR, Zacchello F, Sabetta G, Hale DE 1991 Progressive neuropathy and recurrent myoglobinuria in a child with long-chain 3-hydroxyacyl-coenzyme A dehydrogenase deficiency. J Pediatr 118:744-746

32. Tein I, Donner EJ, Hale DE, Murphy EG 1995 Clinical and neurophysiologic response of myopathy and neuropathy in long-chain L-3-hydroxyacyl-CoA dehydrogenase deficiency to oral prednisone. Pediatr Neurol 12:68-76

33. Lundy CT, Shield JP, Kvittingen EA, Vinorum OJ, Trimble ER, Morris AA 2003 Acute respiratory distress syndrome in long-chain 3-hydroxyacyl-CoA dehydrogenase and mitochondrial trifunctional protein deficiencies. J Inherit Metab Dis 26:537541

34. Zhang J, Zhang W, Zou D, Chen G, Wan T, Zhang M, Cao X 2002 Cloning and functional characterization of ACAD-9, a novel member of human acyl-CoA dehydrogenase family. Biochem Biophys Res Commun 297:1033-1042

35. Lea W, Abbas AS, Sprecher H, Vockley J, Schulz H 2000 Long-chain acyl-CoA dehydrogenase is a key enzyme in the mitochondrial beta-oxidation of unsaturated fatty acids. Biochim Biophys Acta 1485:121-128 